First Peoples Child \& Family Review

A Journal on Innovation and Best Practices in Aboriginal Child Welfare Administration,

Research, Policy \& Practice

\title{
Reflections of a Mi'kmaq social worker on a quarter of a century work in First Nations child welfare
}

\section{Nancy MacDonald and Judy MacDonald}

Volume 3, Number 1, 2007

URI: https://id.erudit.org/iderudit/1069525ar

DOI: https://doi.org/10.7202/1069525ar

See table of contents

\section{Publisher(s)}

First Nations Child and Family Caring Society of Canada

\section{ISSN}

1708-489X (print)

2293-6610 (digital)

Explore this journal

\section{Cite this article}

MacDonald, N. \& MacDonald, J. (2007). Reflections of a Mi'kmaq social worker on a quarter of a century work in First Nations child welfare. First Peoples Child \& Family Review, 3(1), 34-45. https://doi.org/10.7202/1069525ar
Article abstract

First Nations people would argue that the 'Sixties Scoop' of removing their children from their homes and culture never ended. First Nations children entering 'care' of child welfare agencies has increased significantly since the 1960s and 1970s. Storying the journey of a Mi'kmaq social worker working with a First Nations child, aspects of the child welfare system will be theoretically and historically located and critiqued from a social justice perspective. Schools of Social Work will be challenged to provide an education inclusive of decolonization, understanding the historical limitations of the child welfare system and its impact upon First Nations peoples.
This document is protected by copyright law. Use of the services of Érudit (including reproduction) is subject to its terms and conditions, which can be viewed online.

https://apropos.erudit.org/en/users/policy-on-use/ 
First Peoples Child \& Family R

A Journal on Innovation and Best Practices in Aboriginal Child Welfare Administration, Research, Policy \& Practice

Volume 3, Number 1, 2007, pp. 34-45

\title{
Reflections of a Mi'kmaq social worker on a quarter of a century work in First Nations child welfare
}

\author{
Nancy MacDonald and Judy MacDonald
}

\section{Introduction}

A cursory examination of the child welfare

systems for First

Nations children during the past twenty-five years demonstrates that colonialist ideologies have not changed significantly in Canada (Crichlow, 2003; Johnson, 1983; Monture, 1989).

Within this paper First Nations child welfare will be explored through my lens as a First Nations social worker, where I begin my story reflecting on my relationship with a First Nations child, who I will name Cheyenne, that I met when I first began my career. Her story tells of multiple losses, including loss of cultural identity, loss of self and loss of location in the world. Tragically, her story is not an isolated case but could be one of many First Nations children's stories in Canada, who have been taken into care by child welfare authorities. Residential Schools resulted in children being 'scooped' away from their parents, community and culture (Johnson, 1983); the child welfare systems today fulfills that same purpose of assimilation of First Nations children (Crichlow, 2003). First Nations children experience racism and become 'lost' within the system (Palmer \& Cooke, 1996).

Through the storying of my own experiences as a First Nations social worker and through reflecting on the story of one First Nations child, I envision culturally appropriate services and legislations for First Nations children and their families, housed within a social justice perspective. Critical discussions of First Nations child welfare 
agencies, National First Nations Organizations, and Schools of Social Work will highlight areas of concern and potential for change.

\section{Autoethnography and the Process of Storying}

Storying within the narrative tradition is becoming a recognized medium of expression within the social sciences (Bruner, 2002; Ellis \& Bochner, 2000; Riessman, 1993, 2002). Social work's feminist association with the 'personal and political' linkage of experiences (Beverley, 2000; Levine, 1982; MacDonald, 2004), along with Indigenous traditions of honoring and learning from personal stories (Smith, 2001) makes the selection of this method most appropriate. According to Jerome Bruner (2002), a well known educator and psychologist, storying reveals the human condition, specifically attending to "what people are like and what their world is like" (p.90).

Autoethnography is the storying of one's own experiences of the world. It is "an autobiographical genre of writing and research that displays multiple layers of consciousness, connecting the personal to the cultural" (Ellis \& Bochner, 2000, p.739). Using an autoethnographic process of storying allows the text to weave through historical, cultural and political nuances associated with the emotional, spiritual and relational aspects of the story (Ellis \& Bocher, 2000). Within this process it becomes important to move beyond the personal lens to one's story to examine the interplay of experiences within their social context. The story shared below is an example of this interconnectedness, for told outside the political context multiple layers of understanding, along with complex cultural nuances, would be lost. Through detailed reflection I wrote and thought about my early work experiences; I researched the literature and current practices, hence returning to the reflection process with new insights. Subsequently, a iterative backward and forward process of analysis emerged (Clandinin \& Connelly, 2000), by examining the personal, cultural, political and social implications and fractures of the story. Finally by specifically associating them with one particular case that resonated through all aspects of this journey new insights and understandings surfaced.

\section{Beginnings of a Mi'kmaq Social Worker}

My story begins as a very young Mi'kmaq woman when I came into contact with the provincial mental health and child welfare systems in working with a First Nations child. This contact became the point of origin for the journey that I was about to undertake for the next quarter of a century in my professional social work practice. Following my interest, I became an assistant welfare officer with a government department that was responsible for Native welfare. This office was located in a visible site, easy for Mi'kmaq peoples to locate when they came to the 'big city' in search of employment. Often, I was involved in social work related issues with Mi'kmaq people, such as housing, education, and employment; however, as I reflect on my experience, I have come to realize that I was not prepared for the teachings that I was about to receive.

One day my supervisor approached me about a situation that she had encountered with a twelve-year-old First Nations child (whose tribal ancestry was not from this geographic location) who was a resident at the local mental health institution. My supervisor was Mi'kmaq and her cultural identity was more easily recognizable than mine to the nonAboriginal public sector. She explained to 
me that she received a telephone call from the mental health staff working with this child, requesting assistance in the development of a treatment plan. They had diligently tried to reach her for six months, to no avail. My supervisor had scheduled a meeting with this young girl to discuss her concerns and the potential of working together. However, this meeting never materialized as the young girl had an extreme physical reaction immediately upon coming into visual contact with my supervisor. We later found out that this pre-teen had never seen another Aboriginal person and upon visual contact all the stereotypical and prejudicial conditioning came flooding back to her consciousness. As my supervisor could not get physically close to this child, she asked if I would try. I agreed and subsequently made arrangements to go see her. Immediately I recognized the institutional barriers and asked if she wanted to go for a walk, in order to talk in a natural environment devoid of the sterile hospital sights, smells and noises. Our time together became her only reprieve from that brick walled institution. We would go for walks, go bowling, grab a donut or just drive around: we developed a relationship.

\section{Her Story}

Cheyenne was taken from her parents, community, culture and heritage when she was one-years-old by the local child welfare agency in her territory. She was adopted into a non-Aboriginal family when she was just two-years-of-age. The adopting family was in the Canadian military and relocated to a new province shortly after the adoption had become finalized.

The family had two biological children who were both male and much older than Cheyenne. They had not lived at home for some time, as they were both in the Canadian military, following in their father's footsteps. Cheyenne was not connected to them emotionally as siblings and had no real relationship with either of them.

Shortly after the family's relocation, her adoptive mother was diagnosed with cancer, which in the end was terminal. Her mother was a stay-at-home mother while her father traveled extensively with his work. Cheyenne remembers spending most of her time at home feeling very alone and scared, as her mother was very ill. Over time, she had become her mother's caretaker. As her mother became increasing ill, she would be the person in charge to prepare food and provide the personal care needs of her ailing mother. She also remembers the family being isolated within this community for her mother was not able to participate in community events and the father was often unavailable. Cheyenne could not recall friends of the family or relatives visiting at their home.

Her school experiences did not provide a positive source of self-development. She remembers being the only child with a brown face in her school, even in her community. Cheyenne was told "Indians were drunks and bums", and therefore could not care for their children. The stereotypes were reinforced within her own family, as she was told she was 'saved'by being adopted into their white middle class family. She had no friends in school, nobody visited their home. She remembers the mean things the children would say to her because she had a brown face, because she was the Indian. Her mother was her only source of love, but she passed away when the child was just eleven-years-of-age, leaving Cheyenne to feel totally alone in the world.

Within six months of her mother's passing, her father remarried. He married a woman from the community who had three younger children. This blended family had their difficulties, least of which was how they treated Cheyenne. She was the scape-goat, blamed for any family difficulties and considered a negative influence on the younger children. Within six months 
of this new marriage, this child began to exhibit self-harming behaviors. Her father and step-mother drove her to the mental health hospital, dropped her off, and never looked back. They abandoned her.

By the time of my first contact with Cheyenne, she had hundreds of scars on her body, where she tore at her own skin. She literally tried to tear her Indian identity off her body. She had no connection, pride or understanding of her own culture. The stereotypes she had been taught about Indians echoed in her head. The one person who loved her and whom she loved was gone. Cheyenne had given up on life, she did not care about what was happening; she could not envision a future.

As I had grown up with a parent who had attended the Shubenacadie Indian Residential School, I was aware of the destruction and dysfunction that the residential school system caused to Mi'kmaq families and other First Nations families across Canada. What I did not realize was that this child was only the beginning of many children that I would come into contact with as I journeyed down the path of First Nations child welfare work within the Mi'kmaq communities of Nova Scotia. The primary lesson I gathered from Cheyenne's story was the single act of displacement of a First Nations child into a non-Aboriginal adoptive home triggered multiple losses for the child. She was lost to herself, her family, her community, her culture and her heritage. Cheyenne was one of the many First Nations children that became lost in the child welfare system in the 1960's and 1970's. Cheyenne spend one year of her early life in this hospital setting, six months prior to my contact with her, and six months afterwards. Cheyenne slowly decreased her self-destructive behavior and was released into a group home, established for hard to place teenage children who were 'in care' of provincial child welfare authorities. In the 1970 s, there were no mechanisms in place to repatriate or re-connect First Nations children to their biological or extended family, or to their community of origin. Cheyenne did not have the opportunity to re-connect with her biological or extended family, or to her community of origin while in her youth-hood years.

\section{When, Why and How did the Profession of Social Work become involved in First Nations Child Welfare?}

In 1946, a Joint Submission from the Canadian Welfare Council and the Canadian Association of Social Workers to the Special Parliamentary Committee would have significant influence on the revisions made to the Indian Act in 1951. Up to this time, provincial child welfare authorities did not provide services to First Nations peoples living on reserves in Canada. For example, in Nova Scotia, after reviewing the provincial child welfare reports between the years of 1944 to 1959 , it is apparent that no child and family services were provided to Mi'kmaq children or families living in Nova Scotia. In response to recommendations made by the Joint Submission from the Canadian Welfare Council and the Canadian Association of Social Workers, Section 88 was added to the Indian Act. Section 88 was utilized to provide justifiable reasoning for the expansion of provincial child welfare services to First Nations peoples living on reserves. Initially the changes to the Indian Act made little difference in the provision of child welfare services as the Federal government did not provide for additional 'authority' for funding. As noted by MacDonald, Glode and Wien (2005), "Section 88 of the Indian Act did not clarify the financial obligations of the Federal government to the Provinces, the consequences of which would be enduring conflict between the Federal and Provincial governments" (p.358). Lack of federal 
funding to provincial child welfare agencies continued throughout the 1950's and 1960's.

As a result of the lack of clarification on federal funding to provincial child welfare authorities, little change occurred until the 1960s and 1970s in most provinces and Territories in Canada. In 1966, H. I. Hawthorne published a report regarding the disparities in child welfare where he noted that the situation varied from "unsatisfactory to appalling" for First Nations people and recommended "that the provinces should be encouraged to extend all welfare services, including child welfare, and that Indians should be induced to accept them" (Johnston, 1983, p. 3). Through Tripartite agreements, provincial child welfare authorities began to extend child and family services to First Nations peoples living on reserves in Canada. For example, in 1964, a memorandum of agreement was signed between Canada and Nova Scotia that stipulated that Mi'kmaq people living on reserves would receive the same child welfare services provided to other residents of Nova Scotia. The Federal government agreed to pay 100 percent of all cost incurred for the care and custody of First Nations children living on reserves, as well as the total cost of related administrative services. The same arrangement was extended to First Nations children living off reserve in Nova Scotia. These arrangements continued in other provinces, as a result, First Nations children quickly became over-represented in care of the provincial child welfare authorities during these years. Johnston (1983) found that First Nations children represented $40-50 \%$ of the total number of children in care of child welfare authorities, further they were 4 to 5 times more likely to enter care than non-Aboriginal children in Canada.
The provincial child welfare authorities who delivered services to First Nations peoples living on reserves in the 1960s, 1970s and 1980s were largely extensions of the previous residential school system, on the continuum of assimilationalist practices towards First Nations peoples and communities. As Johnston (1983) observed that,

Proponents of this theory point out that in the first half of this century government agencies institutionalized colonialization by removing Indian children from their parents at an early age and placing them in residential schools. In time, it became obvious that education was not the only objective of residential schools. Stories of Indian children being beaten for speaking their own language seeped into the public consciousness and, eventually, began to discredit the residential school system. Gradually, as education ceased to function as the institutional agent of colonialization, the child welfare system took its place. It could continue to remove Native children from their parents, devalue Native custom and traditions in the process, but still act 'in the best interest of the child'. Those who hold to this view argue that the Sixties Scoop was not coincidental; it was a consequence of fewer Indian children being sent to residential schools and of the child welfare system emerging as the new method of colonization (p.24).

Twenty years after the extension of provincial child welfare services on reserve, Johnston (1983) noted that one longtime employee of the Ministry of Human Resources in B.C. referred to the process of removing First Nations children from families and communities as the "Sixties Scoop". This longtime employee "admitted that provincial social workers would, quite literally scoop children from reserves on the slightest pretext. She also made it clear; 
however, that she and her colleagues sincerely believed that what they were doing was in the best interests of the children. They felt that the apprehension of Indian children from reserves would save them from the effects of crushing poverty, unsanitary health conditions, poor housing, and malnutrition, which were facts of life on many reserves" (p.23). Provincial child welfare workers held First Nations people accountable for the conditions in which they largely had no control. As a result, thousands of children, particularly, in the western provinces were apprehended by provincial child welfare workers and placed in non-Aboriginal foster and adoptive homes on both sides of the Canadian and United States border. Johnston (1983) notes that "an official from the state of Maine, for example, estimates that almost one-half of Indian children in their care have some affiliation with Canadian bands" (p.19). As a result of First Nations children being placed in foster and adoptive homes in the United States, First Nations leaders, particularly in Manitoba began to express their anger in response to this situation (Johnston, 1983, p.18). These leaders instituted a moratorium on the placement of First Nations children outside the country. "As of mid-1982, therefore, policies and practices in effect in all jurisdictions in Canada prohibited the placement of Native children in foster and adoption homes in the United States except in unusual circumstances. Nevertheless, there continue to be allegations made that Native children from Canada are being 'marketed' in the U.S. in large numbers" (Johnston, 1983, p.18).

\section{How Can the Profession of Social Work be Paved?}

There were various factors that led to this phenomenon of mass apprehensions of First Nations children by provincial child welfare (C) Nancy MacDonald and Judy MacDonald workers once the residential schools began to close their doors in the 1960's. One such factor is that the training and education in Schools of Social Work have not been 'neutral' in their role of developing social work practice standards that are applicable, and perhaps relevant, to First Nations peoples and communities. Sinclair (2004) notes that "the educational agenda for Aboriginal people in Canada was also designed from within an assimilationalist perspective and had the goal of acculturation of Aboriginal people to a western way of living and thinking" (p.51). Many Aboriginal students in Schools of Social Work continue to find these programs to be an alienating place as their cultural values, history and worldviews are not widely represented in curriculum or amongst the faculty (Monture-Angus, 1995; Sinclair, 2004). Aboriginal students are dispossessed from their own race and ethnicity through experiencing the invisibility of the Aboriginal worldview within Schools of Social Work. Cross-cultural perspectives focusing on understanding difference among cultures has recently been the objective of social work training, rather than on decolonizing social work practices in Schools of Social Work in Canada.

Western theory, pedagogy and practice is evidenced in the actions of early social work pioneers who genuinely believed that removing a First Nations child from his or her parents, community and culture due to poverty and poor housing conditions was in the child's best interest. The social workers were acting out of good intentions. They followed the teachings from their educational background in social work and stayed within the mandate of their provincial child welfare agencies.

With the number of First Nations children in care increasing in provincial child welfare 
agencies, it is evident that this method of colonization continues today. Crichlow (2003) states, that "the child welfare system as an extension of the Indian Act is, in essence, the new Western colonization disease" (p.92). Schools of Social Work continue to struggle with the concept that the Aboriginal worldview is not just another social work perspective. It is a paradigm, as real to First Nations people as Eurocentric or the Western paradigm is to peoples originating from Europe. Not only do Schools of Social Work need to address the problem of how to educate Aboriginal social workers, they need to address the problem of how to train non-Aboriginal social workers to provide decolonizing social work practices and strategies when working with the Aboriginal populations.

The legal system also contributes to this over-representation. Crichlow (2003) states, "mainstream legal doctrine is dominated by the focus on individual rights, and this is not applicable or relevant to Aboriginal communities, where the rights of the community take precedence over the individual" (p.94). Johnston (1983) argued in the 1980's that First Nations children and families were the recipients of discriminatory treatment and practices. Today, racism and discriminatory treatment continues to be evident in child welfare systems for First Nations and other Aboriginal peoples in Canada (Palmer \& Cooke, 1996); as evident in the application of standards for the best interests of the child. Socio-economic factors such as poverty, overcrowded housing, and poor sanitary conditions continue to prevail as justifiable reasons for apprehension.

Racism continues to play out in the child welfare systems in Canada. Crichlow (2003) and Monture-Angus (1989) have argued that the Canadian courts have negated the importance of First Nations culture, identity, and heritage as a right of First Nations children, thereby, placing children for adoption as a consequence of the 'best interest of the child test'. They have noted that these 'tests' have been developed by judges and are based on the 'colonial western disease' in that they are doomed to fail in application to First Nations people by the very nature of the test itself. As Crichlow (2003) puts forth, "a judge is asked to act in the best interests of a child as an individual. In order to do so, the judge must be able to empathize with circumstances from all parties in question for his or his intuition to be most appropriate, otherwise, her decision is only an uneducated guess" (p.100). It has become evident that in Canada, the courts have adopted a colour, culture and race blind approach to judicial decisions that reflect false underlying assumptions of objectivity and neutrality. The 'best interests of the child test' relies on the presumption of objectivity and empathy, however, evidence indicates judicial decisions to be riddled, time and time again, with the interests of the dominant culture being protected, rather than the protection of the child's rights. Law, provincial child welfare authorities, and Schools of Social Work have preferred white hegemonic philosophies and practices towards First Nations people in Canada. The rights of the individual has preceded the rights of the collective in all of these institutions. Crichlow (2003) has also noted that although some progress may have been made to recognize First Nations culture and heritage in judicial decisions, the progress will be limited until First Nations people have the ultimate right to self-determination, without interruption from government. 
Farris-Manning and Zandstra (2003) noted, "Article 2 specifies that all children have a right to be protected from all forms of discrimination" (p.16). Johnston (1983) noted twenty years previously, "the protection afforded by the state has been denied to some children and families for no other reason than that they are Indian" (p.67). In addition to the racism and discriminatory practices observed in Provincial Courts, Provincial child welfare systems, and by Schools of Social Work, the governments also continue to fuel colonialism of First Nations peoples. These jurisdictional disputes continue to be a factor impacting children and families living on and off reserves in Canada. Specifically, in relation to the delivery of culturally appropriate services to First Nations peoples living on reserves in Canada today.

\section{Reflections of a Mi'kmaq Social Worker on Twenty-Five Years of Practice}

In the mid 1970's First Nations child welfare programs began to develop. In Manitoba, two Tribal Councils began to run their own child welfare agencies. The first was the Fort

Alexander Band in 1976, when it signed an agreement with the Department of Indian Affairs to begin its own child welfare agency. The second was the Pas Band which followed with a similar initiative in 1977. These two Tribal run agencies set the president for First Nations child welfare agencies to develop across the country. First Nations child welfare agencies began to develop in significant numbers in the 1980's, spreading from reserve to reserve, from province to province. In 1985, the First Nations Child Welfare agency opened its' doors in Nova Scotia and it began to provide child welfare services to the thirteen Mi'kmaq reserves in the province.
My journey into First Nations child welfare continued when I became employed as a 'junior' supervisor of child welfare services at this agency when it opened its' doors in September of 1985. During my fifteen years of providing direct child welfare practice to First Nations children and families at this agency, I had encountered numerous children that shared similar stories of adoption breakdowns in nonAboriginal homes as did Cheyenne, the First Nations child storied in this paper. As a result of First Nations peoples hearing similar stories from children and adults in their communities, First Nations people have come to distrust social workers and are suspicious of 'good intentions'. Sinclair (2004) stated "social work has negative connotations to many Aboriginal people and is often synonymous with the theft of children, the destruction of families, and the deliberate oppression of Aboriginal communities" (pp.3334).

Even though First Nations communities have been providing their own child welfare services for twenty plus years, First Nations children continue to represent the fastest growing percentage of children in care of child welfare authorities in Canada (Blackstock, APTN National News, November. 9, 2004). Cindy Blackstock (2004), Executive Director of the First Nations Child and Family Caring Society of Canada, reported that First Nations children have a one in seventeen percent chance of entering the child welfare systems in this country, as compared to one in two hundred percent for non-Aboriginal children. Manitoban First Nations children (status and non-status) represent the highest proportion of children in care in Canada, as they represent $78 \%$ of the total number of children in care in that province. Nationally, the average of First Nations children entering care is $40 \%$. Clearly the numbers have 
drastically increased since the 1960's and 80's. Many First Nations people would argue that the Sixties Scoop never ended, it just increased with intensity, each year, each decade. Racism and colonial practices in provincial child welfare systems continue to be challenges for First Nations children and families.

Palmer and Cooke (1996) noted that the overrepresentation on First Nations children in care reflects a long-term government policy of assimilation, a policy that can be viewed as an "aggressive expression of ethnocentrism" (p.711). The majority of First Nations children apprehended by child welfare agencies in Canada continue to be placed in non-Aboriginal families. Elliot and Fleras (1992) believe, "subtle forms of discrimination continue to interfere with the lives and life chances of various racial and ethnic minorities" (p.44). Palmer and Cooke (2003) further acknowledged;

Caucasian foster careers or adoptive parents have no natural supports for First Nations children, and the children are vulnerable to internalizing ethnocentrism and prejudice. The records of Native children in foster and adoptive homes contain repeated stories of their efforts to scrub the brown color from their skins (p.719).

Cheyenne's story continues to be retold.

McKenzie and Morrisette (2003) state the current era in child welfare systems is characterized by three factors; the growing acknowledgement of self-government rights as sovereign or absolute rights; the importance of land claim settlements based on Aboriginal title which confers Aboriginal rights over the use of land and resources where ownership has not been legally extinguished and transferred to the Crown; and the increased recognition and awareness of an Aboriginal worldview and of related cultural practices and traditions as an important strength in First Nations communities. Although these factors may be contributing to the lack of development to culturally appropriate and relevant child welfare services, they do not speak to the increasing numbers of First Nations children entering care each year as a result of racism, discrimination and culturally inappropriate 'tests' when determining the best interests of First Nations children and families.

In 2004, a quarter-of-a-century after beginning my journey into child welfare with First Nations children and families, I attended the 5th Annual National Child \& Family Services Conference, in Calgary. This conference was primarily focused on permanency planning issues for children in care. At this conference, I witnessed Phil Fontaine, National Chief of the Assembly of First Nations state, that "child welfare legislation for

Aboriginal Peoples in Canada is not acceptable, until we can exercise full control over our children, anything else is only an interim". First Nations child welfare agencies, as well as National First Nations and other Aboriginal organizations, given their wisdom and experience need to play an active role in the development of culturally appropriate child welfare services and legislation. Action must be taken, for our children will continue to suffer, feeling the strains of racism and deepseeded losses of family, culture, community and identity.

\section{Conclusions about Schools of Social Work from a Mi'kmaq Perspective}

Schools of Social Work must take an active leadership role in the preparation of Aboriginal and non-Aboriginal students for professional social work practice. Culturally appropriate 
perspectives along with decolonizing social work practices need to be taught to all students so that they can work effectively with First Nations peoples in Canada.

In addition to the First Nations child welfare agencies and National First Nations Organizations, Schools of Social Work need to play an active and lead role in the development of culturally appropriate and relevant social work education. Through a social justice lens, the Schools of Social Work need to examine their role in the colonial processes that continue to impact on First Nations people in this country. It is clear that the social work profession and the Schools of Social Work have not been 'neutral' in the education and training that produced the social workers in the profession of the past. As noted by Sinclair (2004) "western theoretical hegemony manifests primarily in educational institutions. The most harmful assumptions are that western thought ought to be the standard educational platform, is automatically relevant and valid, and is universally applicable" (p.51). These are difficult challenges for Schools of Social Work to undertake, for it must be understood that "the Aboriginal approach to education is more than a difference in perspective" (Sinclair, 2004, p.55). In critically examining the non-neutrality of social work education, Schools of Social Work, through the principles of social justice, can take a lead role on becoming a decolonizing agent to First Nations peoples in Canada.

Child Welfare courses in social work programs have been long in existence in Schools of Social Work in Canada. Some Schools are providing courses on child welfare with Aboriginal populations; however, they are not offered on a continuous basis and are usually classified as an elective course. This seems ironic considering the percentage of First Nations children in care of child welfare authorities in Canada. Schools of Social Work need to take a lead role in acknowledging the necessity of Aboriginal faculty in Schools of Social Work to teach decolonizing practices to all students in social work programs. Through a social justice lens, schools could be more proactive in producing social workers who are equipped to address colonial practices and are capable and motivated to collaborate with First Nations child welfare agencies and National First Nations Organizations. Schools of Social Work, through the principles of social justice, have an obligation to provide social work education that is relative and appropriate to First Nations people in Canada, which is not currently being achieved in Schools of Social Work across Canada.

Sheafor and Horejsi (2006) define social justice as one of the most fundamental values for social workers, where fairness and moral rightness in how social institutions such as governments, corporations, and powerful groups recognize and support the basic human rights of all people. Social workers have long believed the fundamental principle in child welfare that children should not be removed from their families solely on the basis of poverty, however, this same fundamental principle has not been applied in provincial child welfare practices towards First Nations parents and children. Furthermore, Sheafor and Horejsi (2006) stated:

Every human being is intrinsically valuable. This worth is not something that must be earned or proved, nor is it a function of one's skin color, nationality, gender, social status, health, education, political affiliation, occupation, or other external characteristic or life circumstance. Simply by virtue of being human, every person has a right to be 
Reflections of a Mi'kmaq social worker on a quarter of a century work in First Nations child welfare

treated with fairness and respect, protected from the abuse and exploitation, and granted opportunities to have family, a basic education, meaningful work, and access to essential health care and social services (pp. 23-24).

Cheyenne did not experience fairness and moral rightness in the child welfare system, nor do many other First Nations children, therefore, it is an issue that Schools of Social Work need to seriously reflect upon when decisions of programming and curriculum are made. As a Mi'kmaq social worker and now as a Mi'kmaq woman who teaches at a School of Social Work, I can envision the connections and opportunities that could result, if we advocated for the inherent rights of First Nations children and families in Canada. However, First Nations faculty can not do this alone. We all need to take responsibility, to respond to historical and current injustices that have affected our most vulnerable community members, our children. As my journey continues, I revisit the stories of the children I have worked with, again hearing through their pain, messages to act, to challenge and to change the system that continues to colonialize First Nations people. In closing, I have storied Cheyenne's life in hopes that it will serve new generations of social workers lessons from First Nations children in hopes they will not have to hear similar stories being retold.

\section{Bios}

Nancy MacDonald is a Mi'kmaq woman, and a registered social worker in the Province of Nova Scotia. Since 2000, she has been employed as a Lecturer at the School of Social Work, Dalhousie University. From 1985 to 2000, she was employed by Mi'kmaw Family and Children's Services of Nova Scotia. Currently, she is completing her Ph.D in Interdisciplinary Studies in Health Professions at Dalhousie University. She has recently become the winner of The Quest Award for 2006-2007 from the Nova Scotia Health Research Foundation and Capital Health for research she is conducting on kinship care in Mi'kmaq and other First Nations communities in Canada throughout her Ph.D studies.

Judy MacDonald is an Assistant Professor at the School of Social Work, Dalhousie University. Her primary areas of work include (dis)Ability, antioppressive social work, social work in health care and specifically chronic pain. Judy recently defended her Ph.D. dissertation at Memorial University entitled: "Untold Stories: Women, in the Helping Professions, as Sufferers of Chronic Pain (Re)Storying (dis)Ability". Judy identifies as a woman with a (dis)Ability and has lived with chronic pain for over 20 years.

\section{References}

Beverley, J. (2000). Testimonio, subalternity, and narrative authority. In N. Denzin \& Y. Lincoln (Eds.), Handbook of qualitative research (2nd ed.), pp. 555 - 565. Thousand Oaks, CA: Sage.

Blackstock, C. (Personal Communication, November 9th, 2004). Aboriginal Programming Television Network (APTN) National News.

Bruner, J. (2002). Making stories: Law, literature, life. New York, N.Y.: Farrar, Straus and Giroux.

Clandinin, D., \& Connelly, F. (2000). Narrative Inquiry: Experience and story in qualitative research.

Crichlow, W. (2003). Western colonization as disease: Native adoption and cultural genocide. Canadian Social Work, 5(1), 88 $-107$.

Farris-Manning, C., \& Zandstra, M. (2003). Children in care in Canada: A summary of current issues and trends with recommendations for future research. Ottawa, ON: Child Welfare League of Canada. 
Retrieved January 10, 2005, from www. nationalchildrensalliance.com/nca/pubs/2003/ Children in Care March 2003.pdf.

Fontaine, P. (2004). Building a stronger future from our past: Through kinship care/ permanency planning [Opening plenary]. 5th Annual National Child \& Family Services Conference, May 31. Calgary.

Elliot, J. L., \& Fleras, A. (1992). Unequal relations: An introduction to race and ethnic dynamics in Canada. Scarborough, ON: Prentice-Hall.

Ellis, C., \& Bochner, P. (2000). Autoethnography, personal narrative, reflexivity: Researcher as subject. In $\mathrm{N}$. Denzin \& Y. Lincoln (Eds.), Handbook of qualitative research (2nd ed.), pp. 733 - 768. Thousand Oaks, CA: Sage Publications.

Johnston, P. (1983). The Canadian Council on Social Development Series: Native children and the child welfare system. Toronto, Ontario, Canada: James Lorimer.

Levine, H. (1982). The power politics of motherhood. In J. Turner \& L. Emery (Eds.), Perspectives on women in the 1980s (pp. 28 -40). Winnipeg, MB: University of Manitoba Press.

MacDonald, J. (2004). One women's experience of living with chronic pain: The proclamation of voice. Journal of Social Work in Disability and Rehabilitation, 3(2), 17 - 35.

MacDonald, N., Glode, J., \& Wien, F. (2005). Respecting Aboriginal families pathways to resilience in custom adoption and family group conferencing. In M. Ungar (Ed.), Handbook for working with children and youth: Pathways to resilience across cultures and contexts (pp. 357 -370). California: Sage.
McKenzie, B., \& Morrisette, V. (2003). Social work practice with Canadians of Aboriginal background: Guidelines for respecting social work. In A. Al-Krenawi and J.R. Graham (Eds.), Multicultural social work in Canada: Working with diverse ethno-racial communities, (pp. 251 - 282). Toronto, ON: Oxford University Press.

Monture - Angus, P. (1989). A vicious circle: Child welfare and the First Nations. Canadian Journal of Women \& the Law, 3, 1 $-17$.

Monture - Angus, P. (1995). Thunder in my soul. Halifax, N.S.: Fernwood Publishing.

Palmer, S., \& Cooke, P. (1996). Understanding and countering racism with First Nations children in out-of-home care. Child Welfare, LXXV (6), pp. 709 - 725.

Riessman, C. (1993). Narrative analysis. Thousand Oaks, CA: Sage.

Riessman, C. (2002). Narrative analysis. In A.M. Huberman and M.B. Miles (Eds.), The qualitative researcher's companion (pp. 217 -270). Thousand Oaks, CA: Sage.

Sheafor, B.W., \& Horejsi, C.R. (2006). Techniques and guidelines for social work practice. 7th Edition. Saddle River, N.J: Pearson Education, Inc.

Sinclair, R. (2004). Aboriginal social work education in Canada: Decolonizing pedagogy for the seventh generation. First Peoples Child \& Family Review: A Journal of Innovation and Best Practices in Aboriginal Children Welfare Administration, Research, Policy and Practice, September 1(1), 49 - 61.

Smith, L (Tuhiwai). (2001). Decolonizing Methodologies: Research and Indigenous Peoples. London: Zed Books Ltd. 